Safety and Security Engineering IX 213

\title{
BEHAVIOR OF ACTIVE AND PASSIVE NOISE REDUCTION PERSONAL PROTECTIVE EQUIPMENT: A CASE STUDY IN A LIMESTONE QUARRY PLANT
}

\author{
GUIDO ALFARO DEGAN ${ }^{1}$, ANDREA ANTONUCCI ${ }^{1}$, GIANLUCA COLTRINARI $^{1}$, \\ DIEGO ANNESI ${ }^{2} \&$ DARIO LIPPIELLO ${ }^{1}$ \\ ${ }^{1}$ University of Rome 3, Italy \\ ${ }^{2}$ Italian Workers Compensation Authority (INAIL), Italy
}

\begin{abstract}
In this study, an estimation of the behavior of three different passive and active personal ear protection equipment was done in order to evaluate their performances when used in a limestone quarry plant. Twenty measure points were chosen for the characterization of the noise emitted in the plant and for the calculation of the workers' noise exposition. Starting from the data we previously measured in laboratory tests, the noise reduction curves, characteristics of each protective equipment, were calculated for different configurations or ways of using. Results show that all the protection equipment are potentially able to reduce the noise level under the lower exposure limit in all the measured positions, but in most of the cases they produce hyper-protection. Differences were found for different ways of using or settings. When earplugs are not properly inserted, the noise could overcome $80 \mathrm{~dB}(\mathrm{~A})$ in some of the points of our case study. When active earplugs are set to the maximum volume, the provided protection wasn't found to be sufficient in all of the noisier points of the plant. In some cases, depending on the spectra and amplitude of the external noise, the sound produced by active earplugs can also be higher than that measured in the external environment. On the contrary, when the earplugs are set on the middle volume, the protection was found to be always optimal. Since noise passing through active earplugs can be attenuated or amplified according to the amplitude of the external noise, the perceived sound is much more homogeneous, especially when passing across points at different noise levels, compared to that provided using passive earplugs. In conclusion, active earplugs, when properly set, could be the better choice, especially in those cases in which workers need to move across points at different noise levels. However, important is to correctly estimate the external noise and the properties of the active earplugs in order to give instruction to workers for their correct settings, so as to avoid both the hyper- than the under- protection.
\end{abstract}

Keywords: active earplugs, quarry noise, ear muffles, noise protection, noise risk, personal protective equipment.

\section{INTRODUCTION}

It's known that in quarry plants workers can be exposed to high levels of noise, due to the presence of noisy machines used for crushing and classifying stones, other than due to the massive movement of trucks and loaders [1]. These noises can represent other than a risk for workers [2], [3], also an environmental problem in those cases in which the plant is not far from urban centers [4], [5]. Solutions as encapsulation with sound-absorbing panels, can sometimes provide good results especially for fixed machines [6], but unfortunately, they are not always easy to apply, depending on the configuration of the plant and the spaces needed for their proper function and inspection. Otherwise, the use of personal protective equipment (PPE) inevitably remains the most common solution for workers' protection [7].

The market proposes many types of PPE, each one having different noise attenuation for different types of noisy sources, depending on both the amplitude of the sound than the frequency spectra [8]. The choice of the proper PPE requires, other than a careful analysis of the noisy sources, also the characterization of the different working tasks and areas in which 
they take place, in order to guarantee good protection and avoiding possible interferences with other protective equipment [9].

In most of the cases in which the exposition to noisy sources varies a lot when moving across different places, a unique PPE it's often unable to satisfy all the properties it should have [10]. This can happen in quarry plants, in which workers don't operate in fixed positions, so the noise they are exposed to can frequently change. In these cases, when passive earplugs or ear muffles are chosen, a compromise of their properties in reducing the noise in all of the areas can't be avoided. What often happens in these cases, is that PPE is chosen in order to be able to guarantee good protection when workers are exposed to the noisiest point of the plant. Anyway, this compromise could result in a hyper-protection against noise in some other points. Hyper-protection can generate difficulties in comprehension of spoken words, annoyance, inconvenience, other than generating safety reduction, since could be difficult to hear alarms or horn signals [11], [12].

In recent years, there has been an increase of active noise protection devices on the market, such as electronic earplugs. These types of PPE, other than made by soft materials that provide the passive attenuation of the noise, are also equipped with an active device consisting of a microphone, a microprocessor, and an amplifier. The active part of the earplugs is able to modify the external sound, also providing an amplification at some frequencies in order to improve the perceived spoken language and reduce the hyperprotection [13].

The behavior of this type of active protection devices varies consequently with the variation of the amplitude of the external sound, following some pre-set curves of attenuation, which are pre-loaded in their software. Sometimes users can also be able to change the configuration of the chosen pre-set attenuation curves, simply by increasing or decreasing what is often indicated as the volume of the device, or simply turning it off. That means that when the device is switched off, the sound attenuation is only provided by the soft material they're composed by, while according to the setting volumes, workers can decide how much the speakers inside the devices will be able to increase or decrease the external sound. These devices would be consequently a good solution especially in those places in which the variation of the external noise does not allow the use of only one type of PPE.

Anyways, the pre-set attenuation curves are studied in laboratory tests at fixed noise emission, such as white or pink noise, and moreover at pre-set amplitudes [14]. That means that in real fields the attenuation of the external noise could not be that expected, and moreover, the speakers inside the device could produce a sound louder than that outside.

Due to the previous considerations, in this paper we aimed to evaluate the efficiency of this type of active earplugs when used in a quarry plant. Starting from some data we previously measured in laboratory tests, an estimation of the attenuation curves used by the software of the earplugs was made, so to be able to approximate their behavior in protecting workers against noise. We also used data from other types of passive protection equipment, in order to be able to compare their behaviors.

\section{MATERIALS AND METHODS}

The measures were taken in the production plant of a limestone quarry located in central Italy. A $1 / 2$ inch free-field microphone connected to a $200 \mathrm{~V}-10 \mathrm{G} \Omega$ preamplifier from Larson and Davis and a four-channel data acquisition system (Soundbook ToughBook CF-19) were used for the measurements campaign. The data were analyzed using the software Samurai. Before and after the measures, the microphone was calibrated using CAL200 - class 1 Larson and Davis calibrator. 
Because the reduction of the production due to the restrictions caused by the pandemic, not all the plant was operative during the period of the present study, so the measure points were chosen only in those areas in which there were functioning machines or other activities.

Twenty measure points were chosen for the characterization of the noise emitted in the plant and for the calculation of the noise exposition in both cases of use and non-use of personal protective equipment (PPE). Most of the measures were taken proximally (between 5 and 15 meters, in the orthogonal projection) to the main production machines, such as rock breaking machines, impact crushers, vibrating sieves, and rotary drum mills. The other measures refer to the rest of the working areas, such as the loading area, the shop, the office and the mess hall. Fig. 1 reports the map of the plant with the measurement points and the machines or the working areas they refer to.

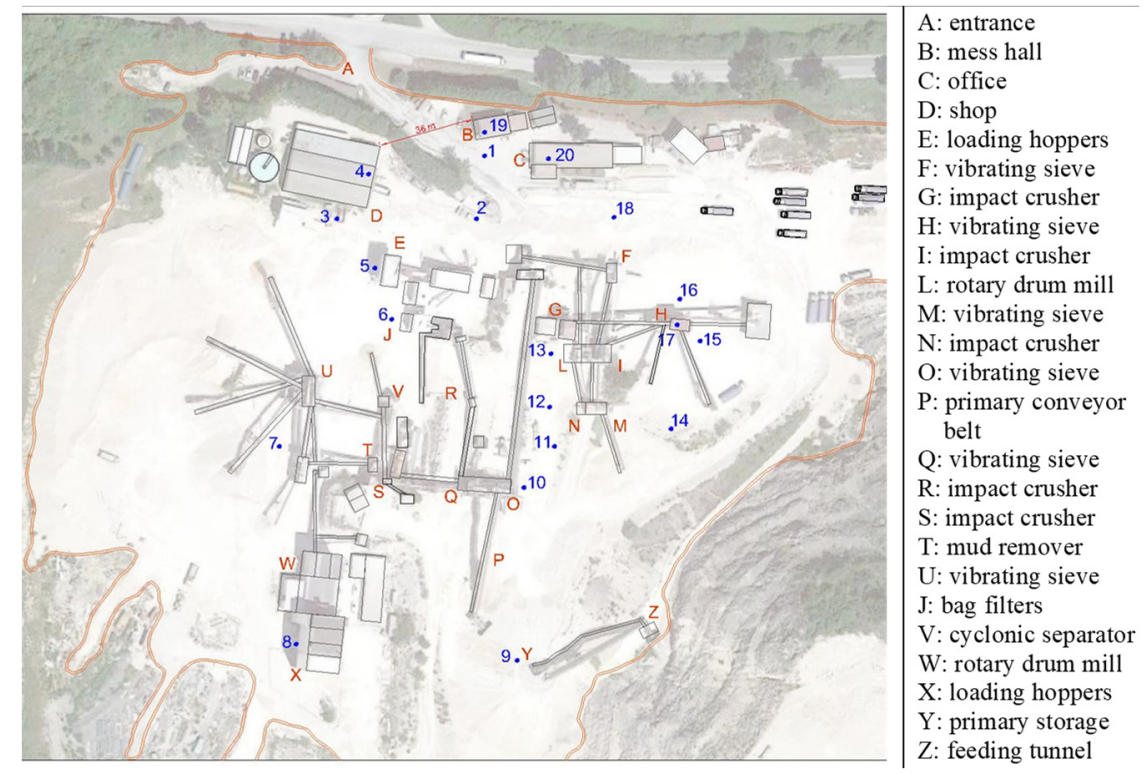

Figure 1: Map of the plant with the numbered measure points and their locations.

Most of the activities in the plant are made using loader machines or other types of vehicles, so workers are partially protected against the external noise by their cabins, moreover in these cases it's not so frequent that workers operate very close to the plant's machines. On the contrary, in those cases requiring inspection activities and/or maintenance, workers operate outside, sometimes very close to the noise sources. Even when the required time for these activities doesn't last long, the amount of noise they are subjected to can be very high. For this reason, the calculation of the daily noise exposition was made supposing that only a part of the working day is spent at the production plant, while the rest of the time is spent in protected locations, such as the office/shop or inside the cabin of the vehicles. Two different scenarios were considered for the calculation, supposing both 5 and 10 minutes of permanence in each of the outside located eighteen positions, and fixing at 1 minute the required time for moving across two consecutive positions. The noise between two consecutive points was calculated as the average of the noise measured at the two fixed positions. Consequentially the two scenarios are as follow: 
1 st case ( $5^{\prime}$ in each position): 109' at the plant; $311^{\prime}$ at the office/shop; $60^{\prime}$ at the mess hall; 2nd case (10' in each position): 199' at the plant; 221' at the office/shop; 60' at the mess hall.

The calculation of the $L_{e x, 8 h}$ was made according to the following equation:

$$
L_{e x, 8 h}=10 \log \frac{1}{T_{0}} \sum_{i=1}^{n} T_{i} 10^{\frac{L_{i}}{10}},
$$

in which $L_{e x, 8 h}$ is the noise exposition of the worker for a working day of 8 hours; $T_{0}$ is the overall time of exposition; $T_{i}$ is the exposition's time for the $i$ th point of measure; $L_{i}$ is the equivalent level of noise measured in the $i$ th point.

A simulation of the noise protection provided by three different PPE was then made. They are as follow: 3M 1100 passive earplugs; Peltor X1A passive earmuffs; 3M Peltor LEP-100 EU electronic earplugs. The PPE were chosen among those able to protect workers at the noisiest point of the plant, other than among those we previously used in other studies. For the characterization of the performance of the active earplugs when used in the present context, we started using the data we previously measured in laboratory tests [13]. The measures were taken in an anechoic chamber, using a mannequin equipped with two microphones inside the head and positioning other two microphones at $10 \mathrm{~cm}$ outside the ears. The tests were made using different configurations of the hearing protection device (switched-off; volumes: 1, 2, 3) and measuring the noise attenuation referring to a speaker emitting pink noise at different amplitudes: $75 ; 80 ; 85$; and $87 \mathrm{~dB}$ respectively.

Regarding the attenuation provided by the $3 \mathrm{M} 1100$ earplugs, other than the data provided by the manufacturer, differences in terms of workers' protection in both the cases in which they are correctly inserted or not, were also estimated. In this case we used the results obtained in another our previous laboratory test [15], in which 100 subjects were asked to wear earplugs before and after the training on their correct use. For these laboratory tests, modified earplugs were used, in which a little plastic tube was inserted in the plugs in order to capture the noise inside the ears by the use of a micro-microphone connected to it. Another little microphone was positioned just outside the ears for the estimation of the noise attenuation. A white noise, generated by a speaker positioned at a fixed distance, was used as signal source.

The attenuation of the PPE in each frequency was calculated according to the equation:

$$
L_{A e q}^{\prime}=10 \log \sum_{f=125}^{8000} 10^{0.1\left(L_{f}+A_{f}-A P V_{f}\right)},
$$

in which $L^{\prime}{ }_{A e q}$ is the noise level resulting from the attenuation; $f$ is the center frequency octave-band from $125 \mathrm{~Hz}$ to $8,000 \mathrm{~Hz}$; $L_{f}$ is the noise level at the considered frequency; $A_{f}$ is the weighting-value (A) for the considered frequency; $A P V_{f}$ is the attenuation of the PPE at each frequency.

\section{RESULTS}

\subsection{Characterization of the plant's noise}

In Table 1 the noise levels measured in each of the eighteen external points are reported, other than the noise inside the office and the mess hall, in terms of linear, peak and weighted values $(\mathrm{A} ; \mathrm{C})$, according to the numbers listed in Fig. 1 . Note that the noise indicated as "office noise" is actually an estimation of the average noise coming from different measures: office, shop and inside the cabin of a truck. This approximation was necessary since we needed an estimation of the average noise exposition of workers when they stay in protected places. 
Table 1: Measurement points and noise levels.

\begin{tabular}{|c|c|c|c|c|c|}
\hline $\begin{array}{c}\text { Measuring } \\
\text { points }\end{array}$ & Location & $\begin{array}{l}\text { Leq } \\
(\mathrm{dB})\end{array}$ & $\begin{array}{c}\text { Leq } \\
(\mathrm{dB}(\mathrm{A}))\end{array}$ & $\begin{array}{c}\text { Leq } \\
(\mathrm{dB}(\mathrm{C}))\end{array}$ & $\begin{array}{c}\text { Peak } \\
(\mathrm{dB}(\mathrm{C})) \\
\end{array}$ \\
\hline 1 & $\begin{array}{l}\text { Outside the mess hall } \\
\text { ( } 40 \mathrm{~m} \text { from the plant) }\end{array}$ & 86.9 & 74.9 & 85.4 & 102.3 \\
\hline 2 & $\begin{array}{l}\text { Open area close to the } \\
\text { gasoline station } \\
\text { ( } 25 \mathrm{~m} \text { from the plant) }\end{array}$ & 89.3 & 78.1 & 88.1 & 103.0 \\
\hline 3 & $\begin{array}{l}\text { Outside the shop } \\
\text { (20 } \mathrm{m} \text { from the plant) }\end{array}$ & 85.6 & 74.3 & 84.6 & 99.1 \\
\hline 4 & $\begin{array}{l}\text { Inside the shop/entrance } \\
\text { (18 } \mathrm{m} \text { from the plant) }\end{array}$ & 85.2 & 73.5 & 84.0 & 98.2 \\
\hline 5 & $\begin{array}{l}\text { Close to loading hoppers } \\
(5 \mathrm{~m})\end{array}$ & 85.3 & 73.1 & 84.4 & 98.5 \\
\hline 6 & Close to bag filters $(5 \mathrm{~m})$ & 95.3 & 83.1 & 94.7 & 107.4 \\
\hline 7 & $\begin{array}{l}\text { Open area not close to active } \\
\text { machines } \\
\text { ( } 70 \text { m from active plant) }\end{array}$ & 80.5 & 70.6 & 79.0 & 95.1 \\
\hline 8 & $\begin{array}{l}\text { Close to loading hoppers } \\
(5 \mathrm{~m})\end{array}$ & 91.7 & 76.3 & 89.4 & 102.1 \\
\hline 9 & $\begin{array}{l}\text { Open area nearby the } \\
\text { primary storage }\end{array}$ & 81.6 & 76.1 & 80.9 & 98.4 \\
\hline 10 & Close to vibrating sieve $(5 \mathrm{~m})$ & 88.4 & 87.4 & 87.9 & 102.5 \\
\hline 11 & $\begin{array}{l}\text { Between vibrating sieve and } \\
\text { impact crusher }(15 \mathrm{~m})\end{array}$ & 89.5 & 88.5 & 89.1 & 112.7 \\
\hline 12 & $\begin{array}{l}\text { Close to impact crusher } \\
(10 \mathrm{~m})\end{array}$ & 93.6 & 92.4 & 93.2 & 112.4 \\
\hline 13 & $\begin{array}{l}\text { Close to rotary drum mill } \\
(5 \mathrm{~m}) \text { and impact crusher } \\
(7 \mathrm{~m})\end{array}$ & 98.8 & 94.8 & 98.2 & 121.0 \\
\hline 14 & $\begin{array}{l}\text { Open area, } 25 \mathrm{~m} \text { from } \\
\text { vibrating sieve }\end{array}$ & 84.5 & 78.4 & 83.3 & 98.1 \\
\hline 15 & $\begin{array}{l}\text { Storage area between } \\
\text { vibrating sieve and conveyor } \\
\text { belts }\end{array}$ & 85.8 & 82.2 & 85.1 & 99.1 \\
\hline 16 & $\begin{array}{l}\text { Storage area between } \\
\text { vibrating sieve and conveyor } \\
\text { belts }\end{array}$ & 87.7 & 83.1 & 87.1 & 100.0 \\
\hline 17 & $\begin{array}{l}\text { On the gangway close to } \\
\text { vibrating sieve }(2 \mathrm{~m})\end{array}$ & 100.5 & 99.7 & 100.0 & 115.0 \\
\hline 18 & $\begin{array}{l}\text { Storage area close to } \\
\text { vibrating sieve }(15 \mathrm{~m})\end{array}$ & 87.0 & 77.0 & 85.8 & 101.3 \\
\hline 19 & Inside the mess hall & 76.2 & 63.5 & 76.0 & 86.1 \\
\hline 20 & Inside the office & 76.8 & 65.5 & 76.3 & 88.8 \\
\hline
\end{tabular}

Results show that the measured noise $\operatorname{Leq}(\mathrm{A})$ exceeds the lower exposure action values of $80 \mathrm{~dB}(\mathrm{~A})$, as established by the European Directive 2003/10/EC [16], in eight points. Most 
of them are located close (less than $15 \mathrm{~m}$, in the orthogonal projection) to the following machines: bag filters, vibrating sieves, impact crusher and rotary drum mills. In 5 of the previous points the noise also exceeds the exposure limit values fixed at $87 \mathrm{~dB}(\mathrm{~A})$. Fig. 2 reports an estimation of the noise levels in the plant, considering those areas functioning during the period of the measurements campaign.

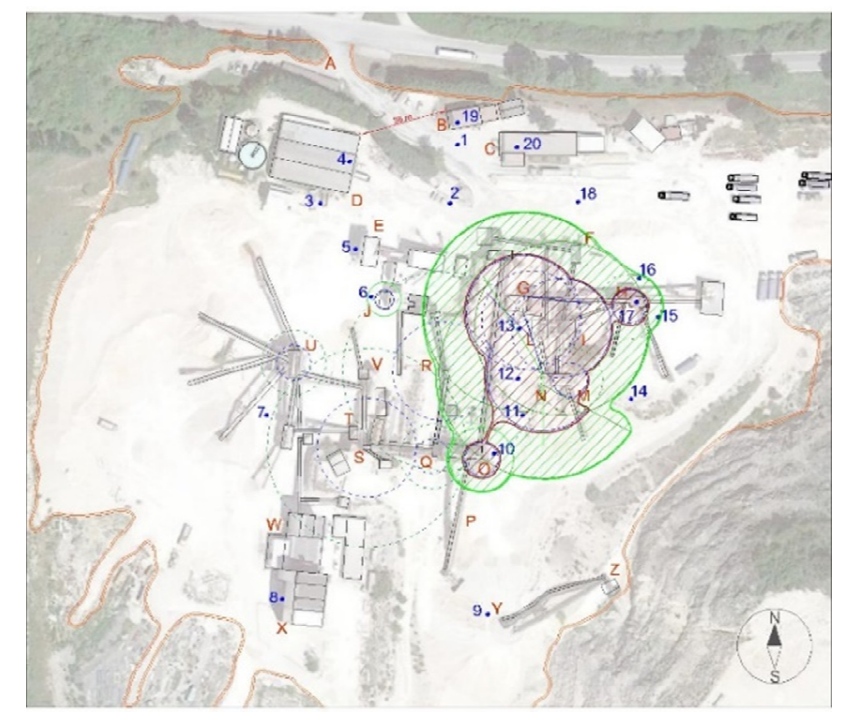

Figure 2: Noise levels in the plant. Red area: over $85 \mathrm{~dB}(\mathrm{~A})$; green area: over $80 \mathrm{~dB}(\mathrm{~A})$.

It's not in the purpose of the present study to obtain a precise characterization of the plant's noise, so these data are intended to be just an approximation of the noise levels emitted in the plant, since the model used does not consider the sound power level emitted by each machine and its direction. In the modeling the noise sources are supposed to be punctual and in free field, without considering reflection surfaces and only partially considering the absorber panels or obstacles positioned around the machines. Dashed circles reported in Fig. 2 represent just an idea of the noise levels that could be in the other part of the plant, when the machines there located are supposed to be functioning. In this case, the same previous made hypotheses of punctual noisy source in free field were made, considering the same noise emitted by similar machines

As shown in Fig. 2, four of the previously indicated points, in which the noise levels overcome the exposure limit value, are located in the same area (points: 10,11,12,13), making it the most critical in terms of noise exposition. The spaces in which the noise could overcome $80 \mathrm{~dB}(\mathrm{~A})$ and $85 \mathrm{~dB}(\mathrm{~A})$ are indicated in green and red respectively. As can be noted, quite all the areas around the functioning plant were characterized by having high levels of noise, requiring workers to be protected.

\subsection{Properties of the tested personal protection equipment}

Fig. 3 reports the noise reduction properties of the passive PPE used in the present study, for each of the octave frequency bands ranging from 125 to $8,000 \mathrm{~Hz}$. As shown in the figure, $3 \mathrm{M}$ earplugs are those performing the higher noise reduction according to the data reported 
by the manufacturer. The range of reduction is between $33.1 \mathrm{~dB}$ at $125 \mathrm{~Hz}$ to $48.8 \mathrm{~dB}$ at $4,000 \mathrm{~Hz}$ with a quite homogeneous increasing protection in the low and high frequencies, followed by a flat behavior in central frequencies. Our previous tests confirmed this behavior, even though at low frequencies, the protection measured when the earplugs are really used resulted to be a little lower compared with that declared. The difference is more marked starting from $2,000 \mathrm{~Hz}$, where the measured protection was found to be quite $10 \mathrm{~dB}$ lower than that reported by the manufacturer.

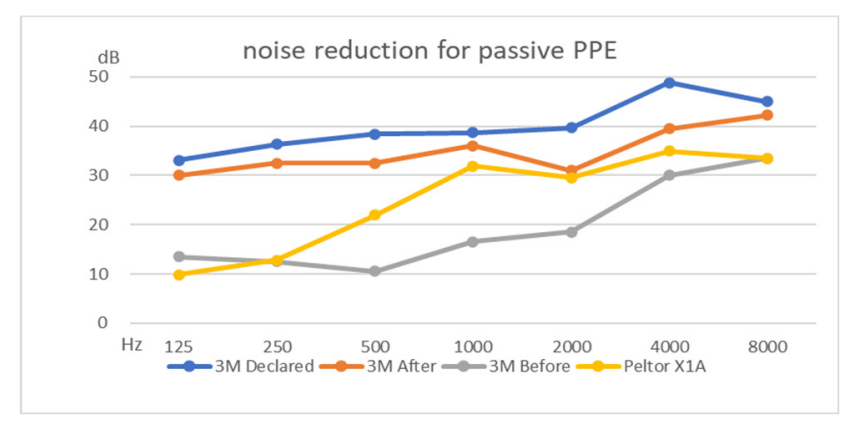

Figure 3: Noise reduction for Peltor X1A earmuff and for 3M 1100 ear plugs as declared by the manufacturer and measured before and after training.

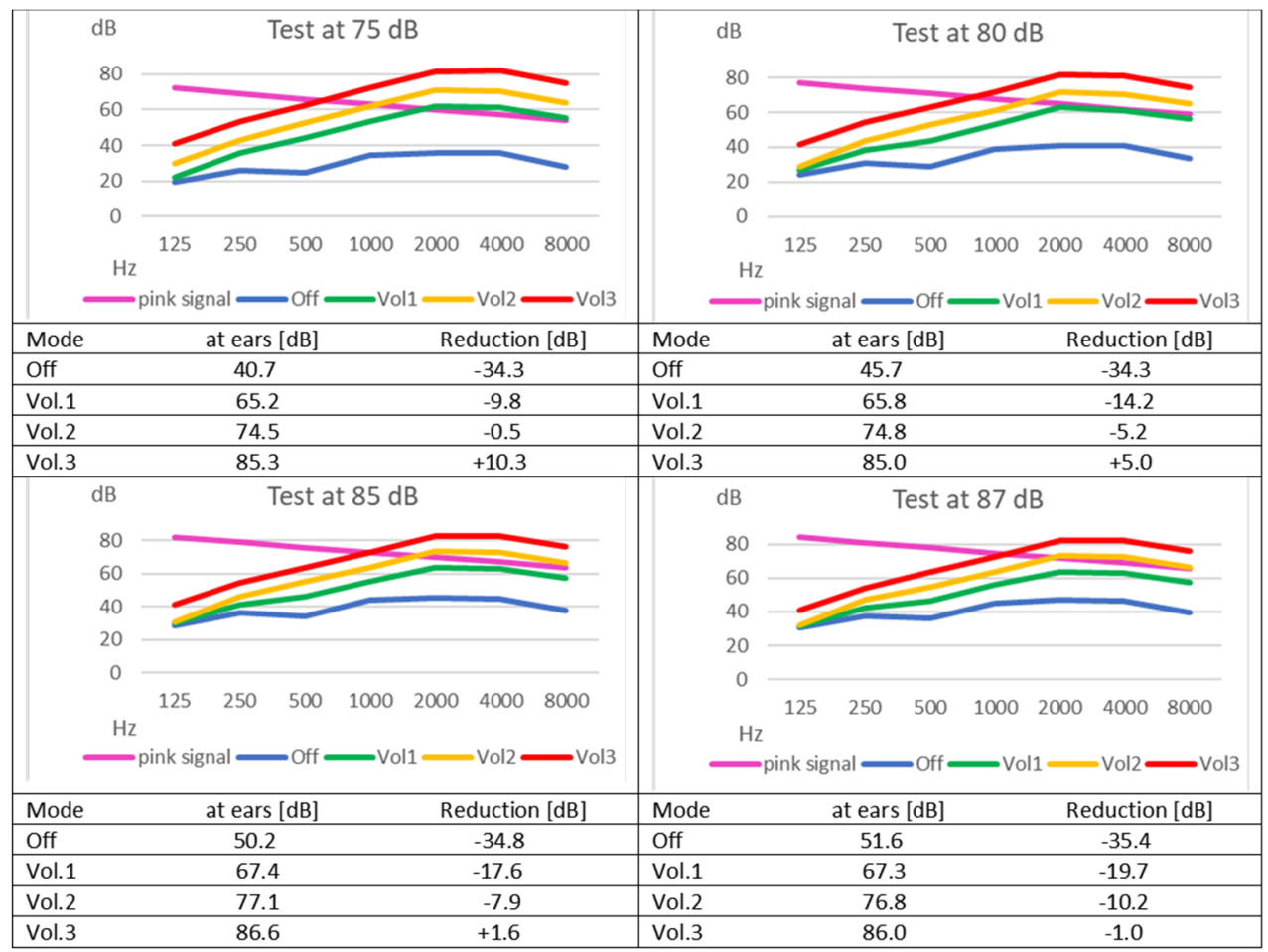

Figure 4: Behavior of the active earplugs at different noise levels. 
When earplugs are not properly inserted, their performances are deeply affected in all the frequency ranges, with a reduction of the protection of about $20 \mathrm{~dB}$ in quite each frequency. For the Peltor X1A earmuffs, we only used the data reported by the manufacturer. These PPE are characterized by performing less noise reduction compared with the $3 \mathrm{M}$ earplugs, especially in the low frequencies range. The overall reduction is between $9.9 \mathrm{~dB}$ at $125 \mathrm{~Hz}$, to $34.9 \mathrm{~dB}$ at $4,000 \mathrm{~Hz}$.

Regarding the active noise control earplugs, in Fig. 4 are reported the data measured in our previous laboratory tests in terms of noise reduction, when pink noise is generated in the anechoic chamber at the different amplitudes of 75, 80, 85, and $87 \mathrm{~dB}$. As shown in the graphs, the performance of active earplugs depends on the pre-set volume, other than on the amplitude of the noise at every single frequency. When the volume is set to 3 , the overall noise at the ears could be also higher than that emitted by the noise source. This behavior can be useful in some circumstances in which the external noise really needs to be amplified, for example for earing spoken communications or alarm signals, but in some other circumstances can also be detrimental. Consequently, when this kind of active earplugs are used in the real field, it is important to carefully evaluate their behavior with respect to the amplitude and spectra of the environmental noise.

For the previous reasons, starting from the data reported above, in the present study we aimed to characterize the behavior of active earplugs when used in the real field, referring to the noise measured in the quarry plant. For this purpose, we first needed to characterize the attenuation or amplification provided by earplugs at every single frequency when varying the amplitude of the external sound. So, we analyzed, at every frequency and pre-set volume, both the amplitudes of the signals emitted by the source in the anechoic chamber, then the noise registered by the microphones inside the mannequin's ears. Results are reported in Fig. 5.

Since the noise emitted by the source in the anechoic chamber didn't reach high amplitude for all the frequencies, in order to be able to rebuild the attenuation curves, we needed to approximate the earplug's behavior at those missing amplitudes. In this case, we supposed that at $99 \mathrm{~dB}$ and for every setting volume, the amplification of the noise provided by earplugs is null. This hypothesis may have a sense, considering that when the noise is very high, it doesn't need to be amplified. In this way, the performances of the earplugs at $99 \mathrm{~dB}$ are supposed to be those provided by the average values, for the same frequency, measured when the pre-set volume is turned off. The noise reduction, starting from the highest measured amplitude in each frequency to the value of $99 \mathrm{~dB}$, was supposed to be linear. Using the previously measured data and following our approximations, we were able to rebuild the attenuation curves that the electronic earplugs follow for reducing or amplifying the noise at each frequency and amplitude. Starting from the previously calculated curves, we estimated the noise reduction of the active earplugs in the hypothesis of their use in our case study. The PPE are supposed to be worn in each of the points in which the measured noise Leq(A) exceeds the lower exposure action values of $80 \mathrm{~dB}(\mathrm{~A})$. Results are reported in Fig. 6.

When the amplification volume of the active earplugs is switched off, the overall reduction of the PPE is provided by the passive behavior of the materials they're composed to. In this case, the attenuation provided by the earplugs reaches its maximum value, that for the quarry plant noise it's estimated ranging between 24.2 to 28.9 decibels. Using the eqn (2), we calculated the performance of the other PPE when used in our context. For the $3 \mathrm{M}$ 1100 earplugs, in the hypothesis of their correct use, the noise reduction should be between 32 and $34.6 \mathrm{~dB}$, providing the higher attenuation; while for the Peltor X1A (only data supplied by the manufacturer) it's supposed to be between 14.4 and $27.1 \mathrm{~dB}$, providing the 


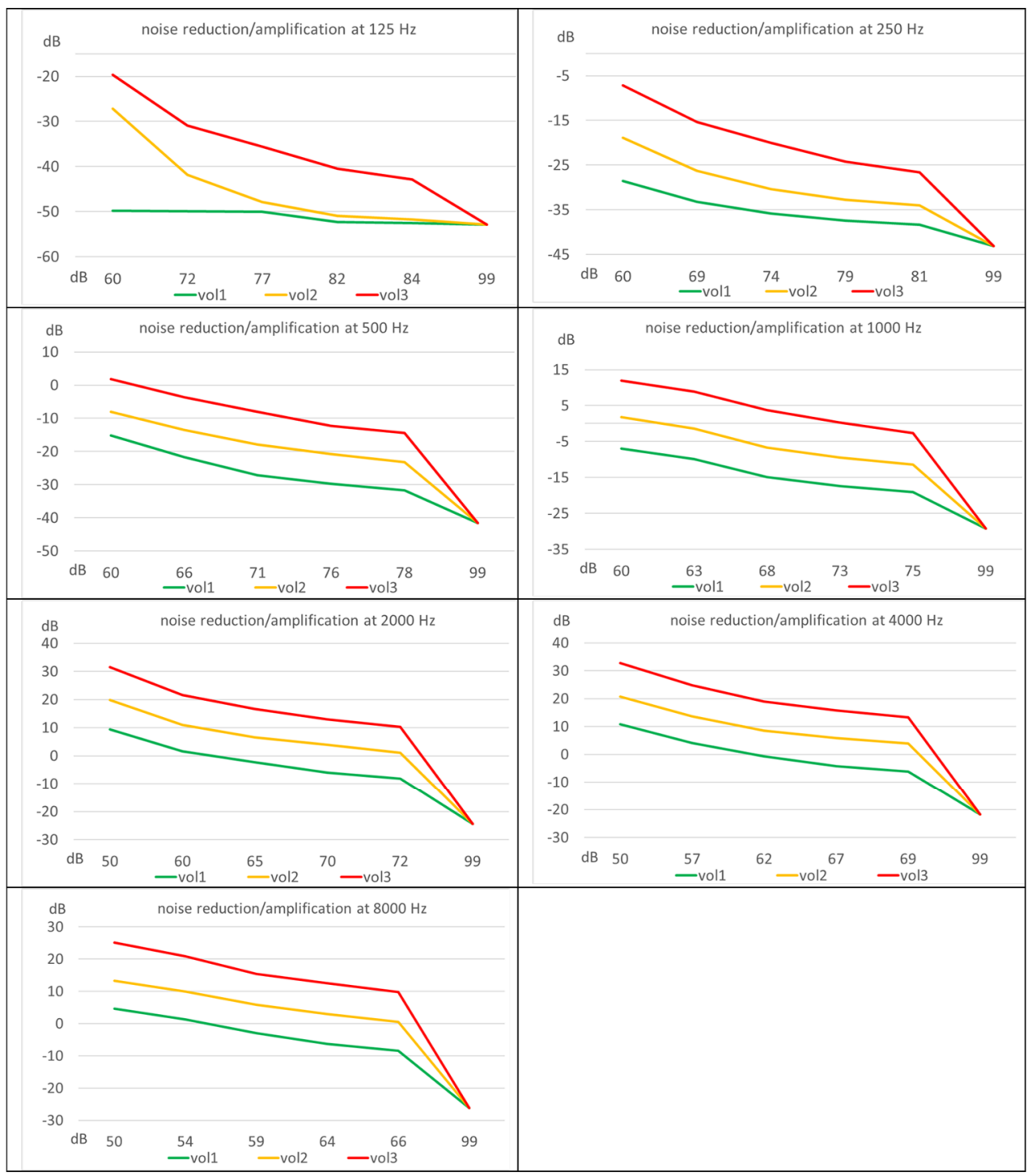

Figure 5: Each graph reports, at the specific frequency, the noise produced by the signal source in the anechoic chamber, measured just outside the ears of the mannequin ( $\mathrm{x}$ axis), and the attenuation or amplification provided by the earplugs (y axis).

lower attenuation. Things change when the active earplugs are turned on. According to the curves previously calculated, at volume 1 they should perform a reduction, in our context, between 11.9 to $22 \mathrm{~dB}$.

As can be seen in Fig. 6, the supposed reduction of the active earplugs is higher in the point $17(22 \mathrm{~dB})$, in which the noise emission is actually the higher $(99.7 \mathrm{~dB}(\mathrm{~A}))$, while they should perform the less reduction $(11.9 \mathrm{~dB})$ in the point $\mathrm{n} .15$, in which the noise measured 


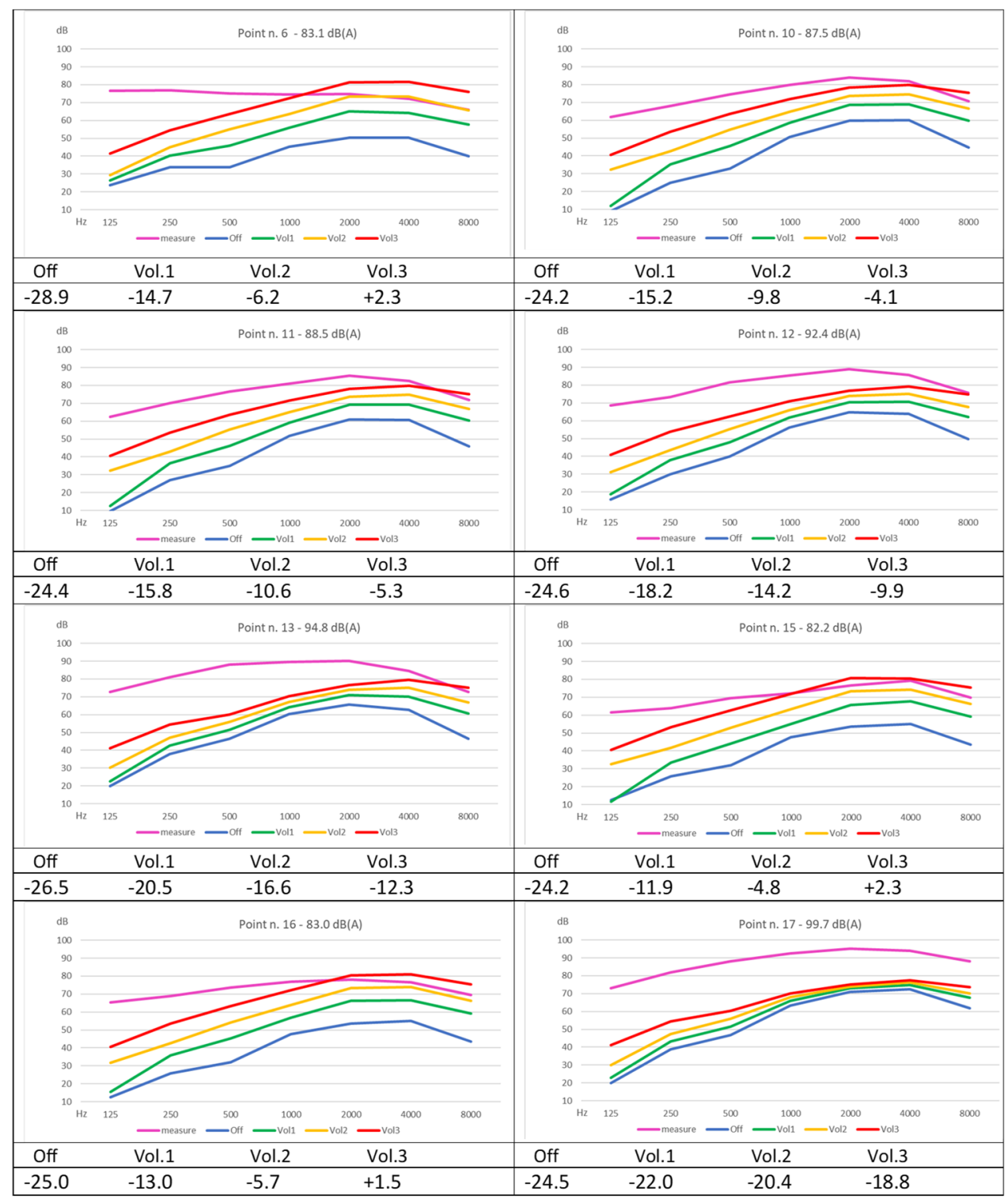

Figure 6: The graphs represent the noise perceived by workers at each point when active earplugs are used at different volumes. The numbers indicate the overall noise at each point and the overall reduction provided.

is the lowest $(82.2 \mathrm{~dB}(\mathrm{~A}))$. The same thing happens for the others pre-set volumes, confirming the good behavior of the active earplugs in reducing more noise when it is at high levels, and providing an amplification when the level is lower. Can also be noted that when the noise reaches high values the behavior of the device, for all of the configurations, is similar to what happens when it's turned off. Anyway, the overall protection doesn't always 
result in the more appropriate when the pre-set volume increases. As can be seen in Table 2, where are reported the attenuation/amplification data estimated for all the examined PPE in all the studied configurations, when the volume of the active earplugs is set to the maximum, they could perform a not enough reduction. In fact, according to our predictions, in this case, the noise perceived at the workers' ears should overcome the lower exposure action values of $80 \mathrm{~dB}(\mathrm{~A})$, in all the noisiest points of the quarry plant.

Table 2: Noise at the ears level after the attenuation/amplification.

\begin{tabular}{|c|c|c|c|c|c|c|c|c|c|}
\hline $\begin{array}{l}\stackrel{0}{\Xi} \\
0 \\
0\end{array}$ & 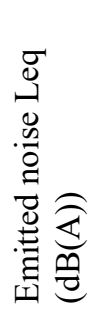 & 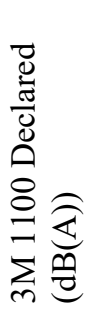 & 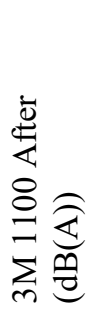 & 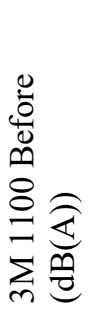 & 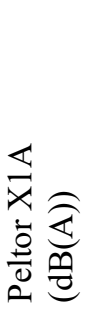 & 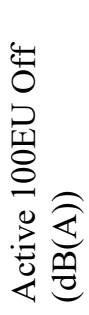 & 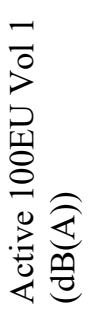 & 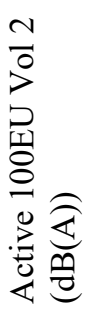 & 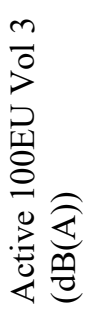 \\
\hline 6 & 83.1 & 46.5 & 50.9 & 69.4 & 68.7 & 54.2 & 68.4 & 76.9 & 85.4 \\
\hline 10 & 87.4 & 46.9 & 54.2 & 69.5 & 60.3 & 63.3 & 72.3 & 77.7 & 83.4 \\
\hline 11 & 88.5 & 48.2 & 55.5 & 71.0 & 61.8 & 64.1 & 72.7 & 77.9 & 83.2 \\
\hline 12 & 92.4 & 52.3 & 59.4 & 75.3 & 66.0 & 67.8 & 74.2 & 78.2 & 82.5 \\
\hline 13 & 94.8 & 55.6 & 61.8 & 80.0 & 71.6 & 68.3 & 74.3 & 78.2 & 82.5 \\
\hline 15 & 82.2 & 40.4 & 47.6 & 63.2 & 56.3 & 58.0 & 70.3 & 77.4 & 84.5 \\
\hline 16 & 83.1 & 43.3 & 49.5 & 66.7 & 60.2 & 58.0 & 70.0 & 77.3 & 84.5 \\
\hline 17 & 99.7 & 59.1 & 66.0 & 82.1 & 73.1 & 75.2 & 77.7 & 79.3 & 80.9 \\
\hline
\end{tabular}

Another thing to note, is that in points number 6,15 and 16 , the noise produced by the active earplugs at vol. 3 should be higher compared to the noise measured in the plant, passing in the worst case from 83.1 to $85.4 \mathrm{~dB}(\mathrm{~A})$. The reason is due to the particular spectra of these sounds which amplitudes result to be higher at the low frequencies, and, much more important, lower to that provided by the earplugs at the high frequencies.

If that estimated behavior should be confirmed in real field measures, the use of this kind of earplugs at volume 3 , other than resulting to be not efficient in reducing the noise under the lower exposure limits, could also be detrimental in some of the quarry points (points: 6 , $15,16)$.

When the volume is set at 2 , the active earplugs should generally perform a good protection, even if at some points the noise passing to the ears is close to the lower action limit.

Regarding the other examined earplugs, their performances seem to be often too high for the noise levels measured in the quarry plant. As can be seen in Table 2, the estimated value of the noise at the worker's ears is often below $65 \mathrm{~dB}(\mathrm{~A})$, resulting in a possible overprotection. When the earplugs are not correctly inserted, there are no cases of over-protection, but on the other side, in the points n. 15 and 16, the noise reaching the worker's ears could be over $80 \mathrm{~dB}(\mathrm{~A})$.

\subsection{Simulation of the noise exposition}

For the previous two hypothesized scenarios, the $\mathrm{L}_{\mathrm{ex}(8 \mathrm{~h})}$ noise exposition was calculated when workers spend 5 or 10 minutes in each of the external eighteen positions located in the quarry 
plant. Results are reported in Table 3. As can be seen, when workers aren't protected, the overall noise exposition exceeds the limits in both the scenarios, resulting over the lower limit value in the first case $(82.7 \mathrm{~dB}(\mathrm{~A}))$ and over the upper limit value in the second (85.5 $\mathrm{dB}(\mathrm{A}))$. When PPE are used, regardless of the model, settings, or proper use, the 8 hours noise exposition decreases under the limits. Anyway, as seen in Table 2, the noise reduction of $3 \mathrm{M}$ earplugs, can easily provide a hyper-protection in some points, while that provided by the active earplugs at volume 3 could be not enough. Moreover, the use of the passive earplugs generates a higher variability of the noise exposition compared to that provided by the active earplugs. In fact, looking at the differences between the maximum and the minimum noise perceived by workers while moving throw different positions, when passive earplugs are used or active earplugs are switched off, the delta is around $19 \mathrm{~dB}(\mathrm{~A})$ (average value between $16.8 \mathrm{~dB}(\mathrm{~A})$ for the Peltor $\mathrm{X} 1 \mathrm{~A}$ and $21 \mathrm{~dB}(\mathrm{~A})$ for switched off earplugs); while at volume 1 it's around $9.3 \mathrm{~dB}(\mathrm{~A})$ and at volume 2 only $2.4 \mathrm{~dB}(\mathrm{~A})$. This is due to the fact that active earplugs tend to amplify the lowest noises and reduce the highest, providing a more homogeneous exposition, especially in those places, as the quarry plants, in which the exposition can varies a lot when moving across different points.

Table 3: $\mathrm{L}_{\mathrm{ex}(8 \mathrm{~h})}$ worker's exposition for both the hypothesized scenarios.

\begin{tabular}{|c|c|c|c|c|c|c|c|c|c|}
\hline & 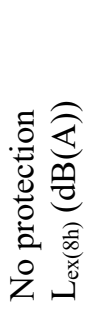 & 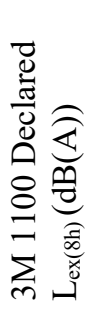 & 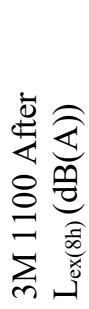 & 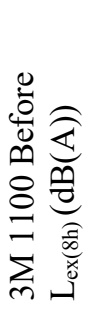 & 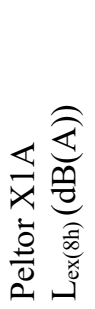 & 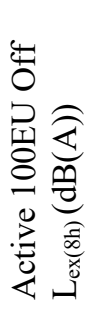 & 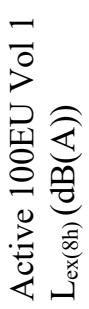 & 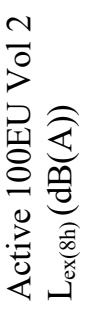 & 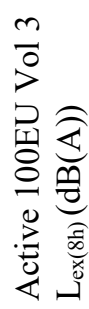 \\
\hline 1st case & 82.7 & 66.5 & 66.6 & 69.4 & 67.2 & 67.2 & 68.4 & 70.4 & 74.3 \\
\hline 2nd case & 85.5 & 69.3 & 69.4 & 72.1 & 69.9 & 69.9 & 71.0 & 73.0 & 77.0 \\
\hline
\end{tabular}

4 CONCLUSIONS

In the present study, different kinds of noise reduction personal protective equipment were analyzed in order to characterize their levels of protection when used in a limestone quarry plant. The activities made in the quarry are characterized by having high levels of noise in most of the areas close to the production's machines, other than a great variability of the noise when moving from a position to another. Even supposing an employee who spends less than 20 minutes in a day working in some of the noisy parts of the plant without any protection, the noise exposition $\left(\mathrm{L}_{\mathrm{ex}, 8 \mathrm{~h}}\right)$ can easily overcome the lower limit value established by the European Directive 2003/10/EC.

Starting from the data of the noise reduction of some PPE measured in laboratory tests, and analyzing their behavior at different amplitudes and frequencies for characterizing their performances, a prevision of the possible protection for a worker that moves around the plant was estimated.

Results show that all the analyzed PPE are able to provide a good attenuation of the noise when used in our case study, even in the case in which earplugs are not correctly worn. Anyway, great variability was observed in terms of protection among those. $3 \mathrm{M}$ earplugs, Peltor X1A earmuffs and active earplugs when turned off, can provide hyper-protection on most of the noisy points of the plant, generating possible discomfort for workers, other than 
difficulties in perceived spoken words or horn signals. On the contrary, active earplugs, when set at the maximum volume, cannot protect properly the workers, sometimes generating more noise than that produced by the machines. Anyway, when the volume of the active earplugs is set on 1 or 2, we generally found a good response of this type of device, resulting the better choice for protect workers in our case study. Results of our simulations show that for the previous settings, the noise at the worker's ears does not overcome $80 \mathrm{~dB}(\mathrm{~A})$ also in case of the external noise at $99.7 \mathrm{~dB}(\mathrm{~A})$ and it never goes below $68.4 \mathrm{~dB}(\mathrm{~A})$. Moreover, since the noise perceived when using active earplugs is attenuated or amplificated according to the amplitude of external noise, the variability of the perceived noise is lesser than that perceived using passive protection devices. So active earplugs seem to be preferred especially in those cases where workers need to move across positions at different noise levels, as often happen in quarry plants.

Anyway, the environmental noise, other than the properties of the active earplugs, must be carefully evaluated before allowing their use, since as shown in the present study, their behaviors are subjected to high variability when the external noise conditions change.

Since this study is modeling-based and moreover, we needed to introduce some approximations for the simulation of the behavior of active earplugs, some differences could be found in their real use. A possible follow-up of this study could be to measure the properties of these active earplugs in the same quarry plant, using the same equipment used in the anechoic chamber, in order to confirm the results here estimated.

\section{REFERENCES}

[1] Pathak, K., Durucan, S. \& Kunimatsu, S., Activity accounting technique for environmental noise assessment in mechanized surface mining. Environmental Monitoring and Assessment, 56(3), pp. 241-256, 1999. https://doi.org/10.1023/A:1005907720627.

[2] Fernandez, M.D., Quintana, S., Chavarria, N. \& Ballesteros, J.A., Noise exposure of workers of the construction sector. Applied Acoustics, 70, pp. 753-760, 2009.

[3] Abel, S.M., Kunov, H., Pichora-Fuller, M.K. \& Alberti, P.W., Signal detection in industrial noise: effects of noise exposure history, hearing loss, and the use of ear protection. Scandinavian Audiology 14(3), pp. 161-173, 1985.

https://doi.org/10.3109/01050398509045937.

[4] Wichers, M., Iramina, W.S., Médici de Eston, S. \& Marques Ayresda Silva, A.L., Using a noise monitoring station in a small quarry located in an urban area. Environmental Monitoring and Assessment, 190(40), pp. 0-11, 2018. https://doi.org/10.1007/s10661-017-6404-6.

[5] Lippiello, D., Alfaro Degan, G. \& Pinzari, M., Comparison of stochastic and deterministic methods for mapping environmental noise from opencast quarries. American Journal of Environmental Sciences, 12(2), pp. 68-76, 2016. https://doi.org/10.3844/ajessp.2016.68.76.

[6] Yang, M. \& Sheng, P., Sound absorption structures: from porous media to acoustic metamaterials. Annual Review of Materials Research, 47, pp. 83-114, 2017. https://doi.org/10.1146/annurev-matsci-070616-124032.

[7] Arezes, P.M. \& Miguel, A.S., Hearing protectors acceptability in noisy environments. The Annals of Occupational Hygiene, 46(6), pp. 531-536, 2002. https://doi.org/10.1093/annhyg/mef067.

[8] Casali, J.G. \& Gerges, S., Protection and enhancement of hearing in noise. Reviews of Human Factors and Ergonomics, ed. R.C. Williges, Vol. 2, Chapter 7, Human Factors and Ergonomics Society: Santa Monica, CA, pp. 195-240, 2006. 
[9] Witt, B., Putting the personal back into PPE: hearing protector effectiveness. Occupational Health and Safety (Waco, Tex.), 76(6), pp. 90-92, 2007.

[10] Acton, W.L., Problems associated with the use of hearing protection. The Annals of Occupational Hygiene. 20(4), pp. 387-439, 1977. https://doi.org/10.1093/annhyg/20.4.387.

[11] Koskinen, H., Toppila, E. \& Makinen, H., Selection of hearing protectors: How to ensure that the end user will get best possible protection? Proceedings of 19th European Conference on Noise Control, pp. 237-241, 2012.

[12] Byrne, D.C., Davis, R.R., Shaw, P.B., Specht, B.M. \& Holland, A.N., Relationship between comfort and attenuation measurements for two types of earplugs. Noise and Health, 13(51), pp. 86-92, 2011. https://doi.org/10.4103/1463-1741.77193.

[13] Alfaro Degan, G., Annesi, D., Antonucci, A., Coltrinari, G., Lippiello, D. \& Nataletti, P., Hearing protection devices with active attenuation control for quarry employment. XXth International Multidisciplinary Scientific Geo-Conference - SGEM, pp. 135$143,2020$.

[14] International Organization for Standardization, Acoustics simplified method for a measurement of insertion loss of hearing protectors of ear-muff type for quality control purposes. Standard ISO/DIS 6290, Geneva, Switzerland, 1983.

[15] Alfaro Degan, G., Coltrinari, G., Lippiello, Nataletti, P. \& Annesi, D., Noise exposure of workers and the correct use of the hearing protection device. XIXth International Multidisciplinary Scientific Geo-Conference - SGEM, pp. 649-657, 2019.

[16] European Parliament, European Directive 2003/10/EC on the Minimum Health and Safety Requirements Regarding the Exposure of Workers to the Risks Arising from Physical Agents (Noise), 2003. 